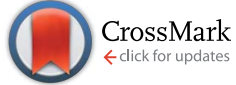

Cite this: J. Anal. At. Spectrom., 2016, 31,2293

\title{
Study of ion beam induced chemical effects in silicon with a downsized high resolution X-ray spectrometer for use with focused ion beams
}

\begin{abstract}
I. Božičević Mihalić, ${ }^{\star}$ S. Fazinić, ${ }^{\star}$ T. Tadić, D. Cosic and M. Jakšić
A downsized wavelength dispersive X-ray spectrometer, employing a flat crystal and a CCD detector for use with focused ion beams has been constructed and employed to study ion beam induced chemical effects in Si K X-ray spectra from silicon and its selected compounds. By using ADP, PET and LiF(110) diffraction crystals, the spectrometer can measure $\mathrm{X}$-rays in the energy range between 1.2 and $8.4 \mathrm{keV}$, with the energy resolution $E / \Delta E(F W H M)=1850$ on $\mathrm{Al} \mathrm{K \alpha}$ and 1580 on Si K $\alpha$ achieved with $2 \mathrm{MeV}$ protons. This energy resolution enables the study of secondary effects in the K X-ray spectra of light elements, L-shell spectra of medium Z elements and $\mathrm{M}$-shell spectra from heavy elements. The K X-ray spectra of silicon and selected silicon compounds were measured after excitation with $2 \mathrm{MeV}$ protons and $20 \mathrm{MeV}$ carbon ions focused to micrometer size. The results obtained for peak relative intensities were analyzed to study their dependence on the silicon oxidation states and effective charge on Si. The results were compared with the existing data obtained by proton, electron and photon induced ionization mechanisms, and clear differences between the ionization sources were observed. Si $K \alpha$ multiple ionization satellites were studied with $20 \mathrm{MeV}$ carbon ions on $\mathrm{Si}_{,} \mathrm{SiO}_{2}$ and $\mathrm{SiC}$. The variation of apparent average $\mathrm{L}$ vacancy fraction $p_{\mathrm{L}}{ }^{x}$ with effective charge on $\mathrm{Si}$ was studied. It has been shown that, for ionization by $20 \mathrm{MeV}$ carbon ions, the relative $K \alpha L^{2}$ intensity is more sensitive to the chemical environment compared to $p_{\mathrm{L}}{ }^{x}$ values.
\end{abstract}

Received 28th July 2016

Accepted 16th September 2016

DOI: $10.1039 /$ c6ja00276e

www.rsc.org/jaas

\section{Introduction}

The particle induced X-ray emission (PIXE) technique has been used for decades as a fast and reliable multi-elemental nondestructive analysis technique for the determination of the sample composition. In a typical PIXE setup, characteristic X-ray radiation emitted from a target irradiated with $\mathrm{MeV}$ energy protons is detected with energy dispersive (ED) spectrometers based on $\mathrm{Si}(\mathrm{Li})$ or SDD detectors. Such detectors have a typical energy resolution of 120-160 eV (at $5.9 \mathrm{keV}$ ). Cryogenic ED detectors of superior energy resolution are available but very seldom used due to their high cost. Even better energy resolution can be achieved with wavelength dispersive (WD) spectrometers with crystals as analysing elements. Such systems are rarely used in PIXE. Commercial WD systems are more common with electron microscopes for applications in mineralogy or geology, where they are usually used to resolve complex X-ray spectra with many X-ray lines common from such samples. Due to their high resolution, the signal to noise ratio in WD systems is much better, resulting in lower minimum detection limits. ${ }^{1}$ However, WD high resolution systems suffer from up to four orders of magnitude lower efficiency as a consequence of the

Ruđer Bošković Institut, Bijenička Cesta 54, HR-1000o Zagreb, Croatia. E-mail: ibozicev@irb.hr; stjepko.fazinic@irb.hr limited reflectivity of dispersive elements and larger distances between the source and the detector. ${ }^{2}$

A major breakthrough for high resolution PIXE (HR-PIXE) was obtained in the 1960s when flow proportional counters replaced photographic detection enabling direct comparison of energies, intensities and shapes of the lines, especially in the case of low-intensity satellites. ${ }^{3,4}$ An important limitation of old WD systems was that step by step scanning detectors were used, requiring stable beam parameters during experiments which was not always easy to achieve, having in mind that many experiments required long measuring times. With the development of position sensitive detectors, like position sensitive proportional counters (PSPC), and recent advances in high performance scientific charge couple devices (CCD) with small pixel sizes, a fertile ground for the wider use of high resolution systems was set. Spectrometers range from commercial ones on electron microprobes ${ }^{5}$ to specially designed systems for dedicated applications, ${ }^{6-8}$ including chemical effect studies on X-ray spectra and studies of secondary effects in X-ray emission of importance for the definition of fundamental parameters in ion-solid interactions.

During the last decade at the Ruđer Bošković Institute (IRB) Accelerator Facility we studied chemical effects on the K $\beta$ X-ray spectra of $3 \mathrm{~d}$ transition metals and their compounds. ${ }^{9-12}$ For these studies we used 2 or $3 \mathrm{MeV}$ broad proton beams 
collimated to $5 \times 1 \mathrm{~mm}$ size from the accelerator as an excitation source and a WD X-ray detection system based on a flat $\operatorname{LiF}(110)$ crystal and a PSPC X-ray detector. Due to low efficiency, typical experiments required ion beam currents higher than $100 \mathrm{nA}$ on targets. While the targets were in a vacuum, all the other components were in a He balloon to reduce X-ray attenuation on the way to the detector (with the sample to detector distance of about $60 \mathrm{~cm}$ ).

PIXE ionization cross-sections for the $\mathrm{K}$ shell are much larger for low $\mathrm{Z}$ elements ( $\mathrm{Na}$ to $\mathrm{Cl}$ ) compared to $3 \mathrm{~d}$ transition metals ( $\mathrm{Ti}$ to $\mathrm{Cu}$ ). Therefore, we planned to extend our studies of $\mathrm{K}$ $\mathrm{X}$-ray spectra to low $\mathrm{Z}$ elements. Such studies are important for two reasons: (i) to exploit the possibilities for the use of chemical effects for chemical speciation, and (ii) to evaluate fundamental parameters like single and multiple ionization probabilities for ion incidence. These issues have been recognized by the International Initiative on X-ray Fundamental Parameters supported by the EXSA (European X-ray Spectrometry Association) $)^{\mathbf{1 3}}$ as very important. For example, the influence of multiple ionization satellites and chemical effects on the PIXE analysis of light elements ( $\mathrm{Mg}, \mathrm{Al}, \mathrm{Si})$ would be important for the exploration of Mars with the APXS (Alpha particle X-Ray Spectrometer) installed on Mars Exploration Rovers. ${ }^{\mathbf{1 4}}$ Due to the low energy of light element X-rays $(\approx 1-3 \mathrm{keV})$, their measurement would require that all the spectrometer components are in a vacuum. Instead of redesigning the existing large broad beam spectrometer, we have used an alternative approach to construct a downsized spectrometer that would be used in combination with the focused ion beams to ensure good energy resolution. In such a way we could combine the downsized spectrometer for applications on microscopic samples utilizing micrometer beam size available at our ion microprobe.

Several downsized spectrometers built in the past were used with broad ion beams in combination with sets of collimators to enable achieving acceptable X-ray energy resolution.,15,16 Their design however required sequential measurements. This approach requires very precise measurements of ion dose on a sample during the acquisition of spectra, which is often not an easy task, and can easily introduce artificial features in the measured spectra due to uncertainties in the dose measurements. Therefore, we decided to use a CCD X-ray detector with good spatial resolution to enable measurements of useful spectra with good energy resolution and an X-ray energy window in a single run. In the past, few groups installed on ion microprobes commercially available WD systems originally designed for electron microprobes but these systems used either flow proportional counters (requiring sequential measurements) or PSPC detectors ${ }^{17-19}$ and were not easily adaptable for the use with ion beams. A relatively large plane crystal spectrometer with a PSPC on a heavy ion microprobe was built by Mokuno et al. for chemical speciation studies, ${ }^{2,20-23}$ demonstrating the possibility of high energy resolution PIXE mapping. ${ }^{21}$

In our system, a plane diffraction crystal geometry has been chosen due to its design simplicity and smallest sensitivity to sample tilt misalignments. We assumed that eventually the spectrometer could be employed for the chemical speciation of hot-spots on structured (non-homogeneous) micro-samples with a lateral resolution in the order of magnitude of $10 \mu \mathrm{m}$. We have focused our efforts to optimise the system to work with ion beams focused to about $10 \mu \mathrm{m}$ or below in the X-ray energy range that corresponds to $\mathrm{K} \mathrm{X}$-rays of light elements from $\mathrm{Al}$ to $\mathrm{Cl}$ (although even higher energies can be measured). A Peltier cooled CCD X-ray detector with good spatial resolution, a flat analysing crystal with a simple linear translator and a sample holder have been enclosed in a specifically designed vacuum chamber. In this work we will describe the developed system and its performances. Capabilities for chemical effect studies will be demonstrated on the $\mathrm{K}$ X-ray spectra of silicon and selected silicon compounds induced by $2 \mathrm{MeV}$ protons and 20 $\mathrm{MeV}$ carbon ions.

\section{Experimental setup}

\section{Spectrometer}

The designed flat crystal spectrometer for HR-PIXE analysis at the ion microprobe covers the X-ray energy range between 1.2 and $8.4 \mathrm{keV}$. Targets can be irradiated with ion beams coming from a $1 \mathrm{MV}$ Tandetron or $6 \mathrm{MV}$ Tandem Van der Graaff accelerator. Both accelerators are equipped with sputtering ion sources, so a wide variety of ions can be accelerated. The focusing system consists of two sets of collimators and magnetic triplet quadrupole lenses, achieving a focused beam spot size of about $10 \times 10 \mu \mathrm{m}^{2}$ on the target in the WD chamber. ${ }^{24}$ With $2 \mathrm{MeV}$ protons we obtained more than $1 \mathrm{nA}$ current on the target, which corresponds to about $10 \mathrm{pA} \mu \mathrm{m}^{-2}$ or more. This current density is below the values used in our everyday work at the ion microprobe standard chamber, where the beam size of about $1 \times 1 \mu^{2}$ and beam current of about $100 \mathrm{pA}$ are typically used. ${ }^{24}$ Basic data about the geometry of the spectrometer equipped with a pentaerythritol (PET) diffraction crystal have already been published. ${ }^{25}$ In the meantime, important upgrades have been done, including upgrade of the system readout and signal processing protocol. An additional crystal has been acquired to extend the detectable X-ray energy range to $\mathrm{Mg}$ and $\mathrm{Al} \mathrm{K} \alpha$ X-rays. With the presently available crystals we can cover two energy windows: between 1.2 and 2.7 keV with PET and ADP (ammonium dihydrogen phosphate) crystals and between 4.7 and $8.4 \mathrm{keV}$ with the $\mathrm{LiF}(110)$ crystal.

\section{Simulation}

Although spectrometers with focusing crystals have larger solid angles compared to flat crystals, they are more sensitive to sample misalignment and complex positioning systems are needed. Therefore, a flat diffraction crystal has been selected in the design. Downsizing of the flat crystal WD spectrometer for ion microbeam application would result in an increased solid angle and consequently greater efficiency, but its energy resolution could be affected significantly. Therefore, numerical procedure XTRACE ${ }^{26,27}$ was used in designing the spectrometer. Fig. 1(a) shows the XTRACE simulated energy spectrum between 2.1 and $2.5 \mathrm{keV}$ for a target consisting of lead, sulphur and mercury obtained with the finally adopted design. These X-ray lines would be largely overlapped if taken with standard SDDs. 
We prepared a real target containing a mixture of two painting pigments: vermilion $(\mathrm{HgS})$ and white lead $\left(2 \mathrm{PbCO}_{3} \mathrm{~Pb}(\mathrm{OH})_{2}\right)$. This combination nicely demonstrates a common situation in ED PIXE (or XRF) analysis when $M$ lines of lead and mercury cause difficulties in quantitative analysis of sulphur due to their overlap with the sulphur K X-rays. Fig. 1(b) shows the spectrum from this target induced with $2 \mathrm{MeV}$ protons and obtained with our HR spectrometer: sulphur K lines are clearly separated from $\mathrm{Hg}$ and $\mathrm{Pb} \mathrm{M}$ lines. The intensity of the sulphur $\mathrm{K} \alpha_{3,4}$ line in the simulated spectrum shown in Fig. 1(a) was artificially increased four times in order to make it clearly visible and to prove its separation from the nearby $\mathrm{S} K \alpha_{1,2}$ and $\mathrm{Pb} \mathrm{M} \alpha_{1,2}$ lines in the simulated spectra.

\section{Crystal}

As wavelength dispersive elements, ADP, PET and $\operatorname{LiF}(110)$ flat analyser crystals have been used. Crystals with dimensions of $70 \mathrm{~mm} \times 11 \mathrm{~mm} \times 35 \mathrm{~mm}$ are attached to a special crystal holder designed to fit inside the chamber. A major limitation on
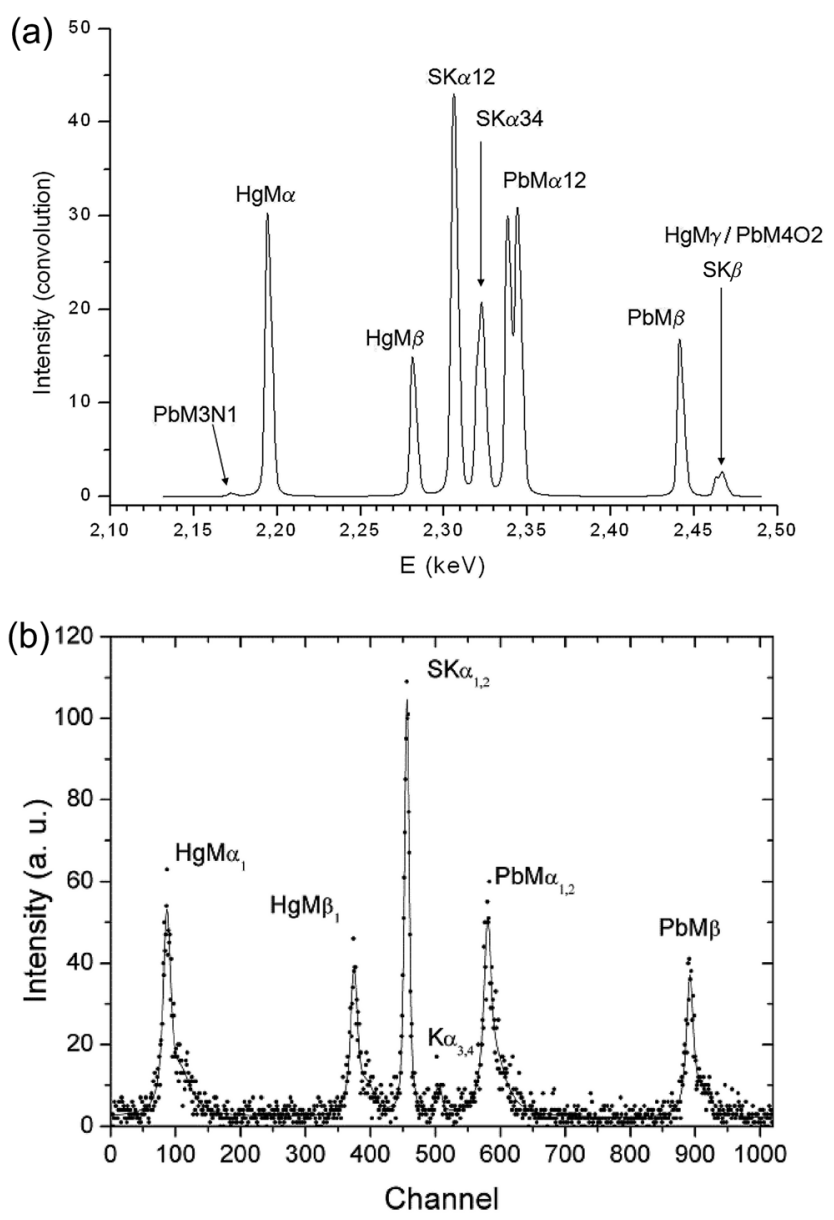

Fig. 1 (a) Expected energy spectrum simulated with XTRACE; (pb, s, hg target); Bragg angle $\theta=38^{\circ}, \lambda / \Delta \lambda=2000$, beam profile Gaussian with $x$ $\mathrm{FWHM}=5 \mu \mathrm{m}, y \mathrm{FWHM}=40 \mu \mathrm{m}$; the spectrum is corrected for the charge spread in the CCD. (b) Spectrum of the target containing a mixture of vermilion $(\mathrm{HgS})$ and white lead $\left(2 \mathrm{PbCO}_{3} \cdot \mathrm{Pb}(\mathrm{OH})_{2}\right)$ pigments induced with $2 \mathrm{MeV}$ protons (dots represent the measured and line fitted spectrum). the detectable energy range for a specific crystal is the size of the WDS chamber and is determined by the crystal minimum and maximum distance from the sample and the detector. Bragg angles covered are $27^{\circ}$ to $57^{\circ}$ and are selected by adjusting the crystal position with a precise micromanipulator outside of the chamber. Three energy ranges are covered: 1.2-2.2 keV with ADP enabling detection of $\mathrm{K}$ lines of $\mathrm{Mg}, \mathrm{Al}$ and $\mathrm{Si}$; $1.5-2.7 \mathrm{keV}$ with PET for $\mathrm{K}$ lines of $\mathrm{Si}, \mathrm{P}$ and $\mathrm{S}$ and $4.7-8.4 \mathrm{keV}$ with the $\mathrm{LiF}(110)$ crystal for $\mathrm{V}, \mathrm{Cr}, \mathrm{Fe}$, Co and Ni K lines.

\section{Data acquisition and signal processing}

Camera control and data acquisition were done with a homemade $\mathrm{C}++$ based program, GreatControl, developed from DLL files provided by the CCD camera manufacturer greateyes. The temperature of the CCD chip and backside of the camera is controlled with the same software to prevent possible malfunction due to overheating. TTL signals from the camera are sent to the ion beam deflector unit which deflects the ion beam from the target to avoid falling of x-rays on the CCD during the readout process. During the measurement, a variety of artefacts could be picked up by the CCD, ranging from secondary electrons escaping the target, backscattered ions from the target to electromagnetic radiation. Secondary electrons are easily stopped in the thin $3 \mu \mathrm{m}$ Mylar film placed in front of the detector. An aluminium shield is mounted around the CCD to block possible X-rays from the target, allowing only photons diffracted from the crystal to reach the CCD. Visible photons pose a problem with targets sensitive to iono-luminescence. In such cases, ion beam induced luminescence (IBIL) can create high background noise in one part or even the whole CCD, and therefore we have used light absorbers in front of the target surfaces. We successfully used thin $5 \mu \mathrm{m}$ aluminized Mylar, $25 \mu \mathrm{m}$ tick beryllium foil, and graphite spray as light absorbers. In case that still some events cannot be blocked with shielding and foils, they have to be removed by the developed offline signal processing procedure of each signal image recorded. Taking into account the energy dispersive character of the pixel detector and selecting a narrow energy region around the energy of the desired X-ray events, all background events falling outside of the selected energy window can be rejected.

Beside the source size and the analysing crystal rocking curve, the spectrometer's energy resolution depends also on the CCD spatial resolution. Although in principle the reduction of the pixel size would increase the CCD spatial resolution, degradation occurs as a result of charge cloud formation and detection of one X-ray photon in more than one CCD pixel. For back illuminated CCD (BI CCD) chips, X-rays enter through the backside, leaving their energy mostly in the field free region. Therefore, induced charge has to diffuse to reach the potential wells defining each pixel. As a consequence, charge can be deposited either in a single pixel or it can be spread to neighbouring pixels causing a split effect. Experiments aimed to measure the charge effect on the $13.5 \mu \mathrm{m} \times 13.5 \mu \mathrm{m}$ pixel size CCD showed that $90 \%$ of the intensity is concentrated in a radius of $18 \mu \mathrm{m}$, leading to spatial resolution which is double the size of the pixel. ${ }^{28}$ For the same pixel sized CCD, Ghiringhelli 
et al. obtained charge spatial distribution with a FWHM of 24 $\mu \mathrm{m}$, with tails of distribution spread to the area extending to more than $20 \mu \mathrm{m}$ in radius. ${ }^{7}$ The ratio of single pixel to split events depends on the energy of detected X-rays, size of the field free region of the CCD and its pixel size. Szlachetko et al. showed that for their BI CCD with a pixel size of $20 \times 20 \mu \mathrm{m}^{2}$, the ratio of single pixel to split events in the case of the silicon $\mathrm{K}$ line is around $40 \%$, falling below $1 \%$ above the Si $\mathrm{K}$ absorption edge. ${ }^{29}$ They also noticed that a major part of the charge was shared between four neighbouring pixels. Most of the algorithms for processing X-ray signals detected in CCDs with a small pixel area accept events falling into a $2 \times 2$ pixel area, discarding those spread out to more pixels. In the case of our CCD, $19 \%$ of the events fall to a single pixel for silicon $\mathrm{K}$ lines (Fig. 2). For S K lines, less than $1 \%$ are single pixel events while $70 \%$ spread to more than $2 \times 2$ pixels and are rejected in standard algorithms. Based on these observations, we developed our image processing procedure which takes into account all events that spread to $3 \times 3$ pixels and fall into the energy window defined around the average charge of single pixel events.

The procedure for event detection is similar to the one described by Szlachetko et al. ${ }^{29}$ From each signal image the mean background image (average of several images without signals - dark images) is subtracted and is followed by the image processing algorithm. Histograms of charge distribution are created, the average charge of single pixel hits is determined from the centre of the peak in Fig. 2 and the energy window is set around it. For split events, the charge spread into a $3 \times 3$ pixel area is summed and if the total sum falls into the defined energy window, value 1 is assigned to the pixel with maximal partial charge while neighbouring pixels are given value 0 . For the signal processing code, it is crucial to adjust the exposure time of single image frames to avoid pileup events that can lead to the total charge falling outside of the energy window. Each processed image is summed together to get a final frame (Fig. 3(a)). The origin of the curvature in

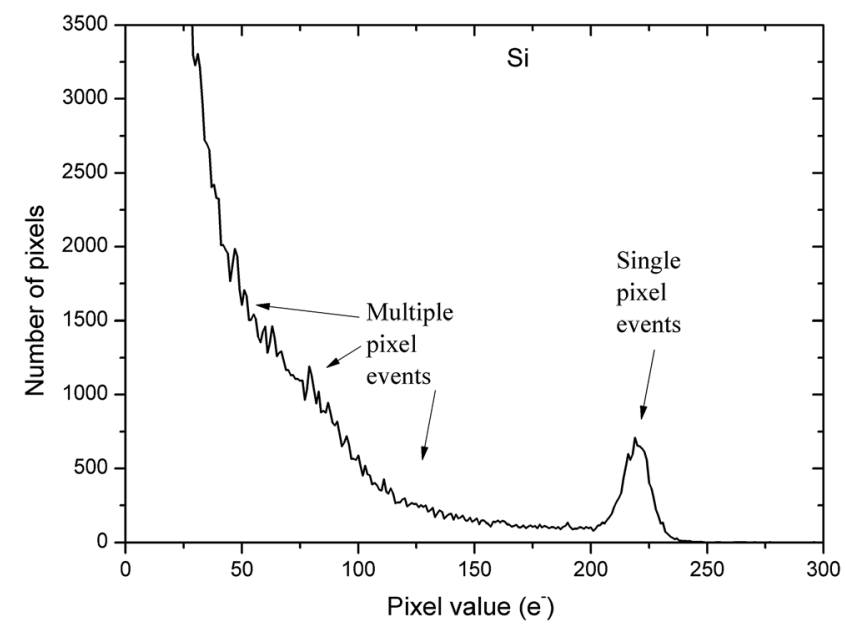

Fig. 2 Histogram of CCD charge distribution for Si K X-rays, single pixel and events with charge spreading to multiple pixels are marked.
Fig. 3(a) is in X-ray diffraction geometric effects due to the finite and relatively large height of the crystal. Due to the fact that X-ray lines in the image are curved, curvature correction on the final frame is performed. The image is cut into 40 horizontal slices. In each slice X-ray lines are fitted with one to multiple Gauss functions depending on the number of lines detected. The dependence of centroids of the Gauss functions in each slice (in most cases the $\mathrm{K} \alpha_{1,2}$ line is the narrowest line) on the y position in the image is determined and fitted with a polynomial function. Shifts are calculated from the difference of the centroid in an individual slice and in the central part of the image. After each slice is shifted for the value of the calculated difference, the final image corrected for curvature is obtained (Fig. 3(b)). X-ray events are projected to the horizontal axis to extract the final spectrum.
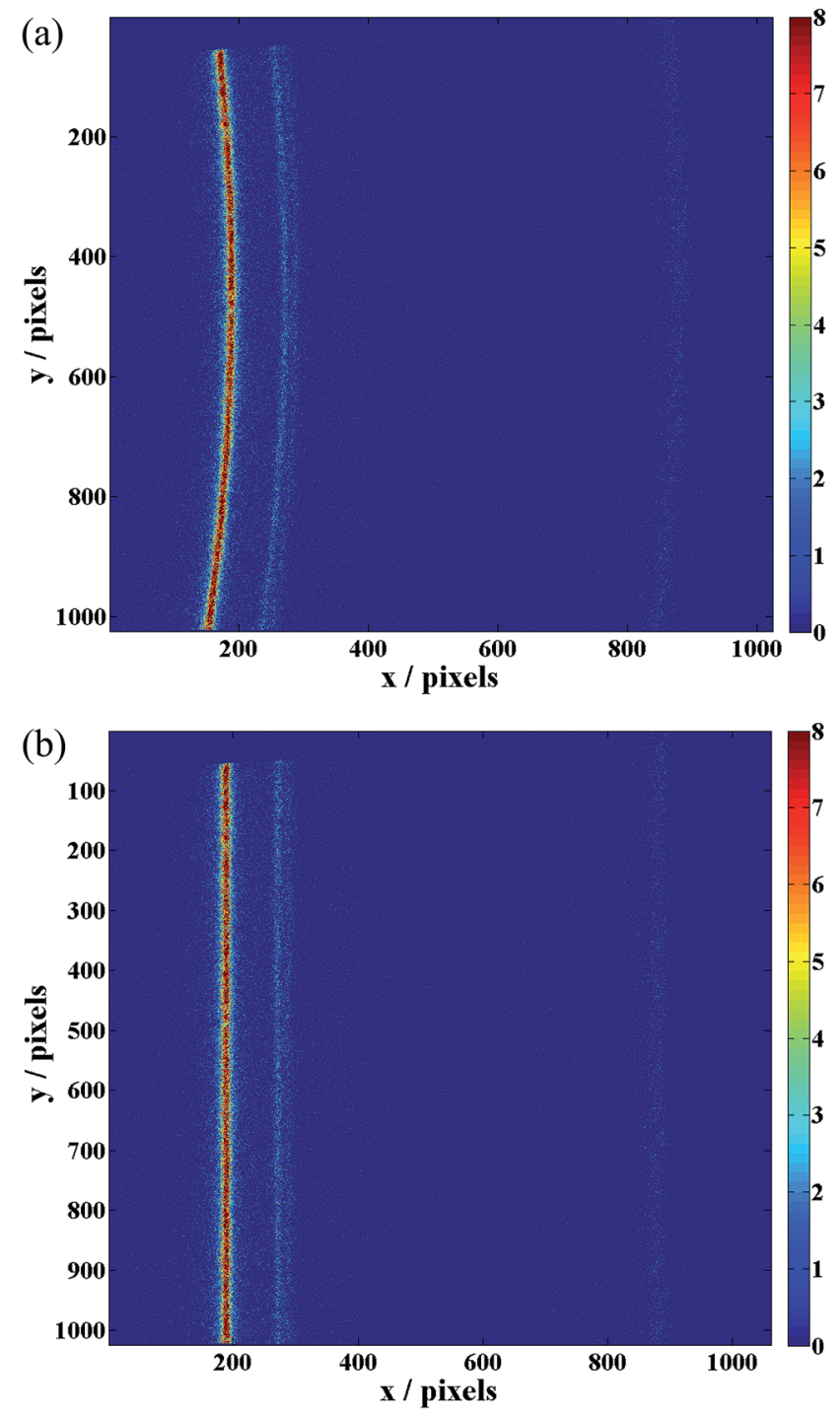

Fig. 3 (a) Final frame obtained after signal processing of each signal frame. (b) Frame after curvature correction. Images show silicon $\mathrm{K}$ lines excited with a $2 \mathrm{MeV}$ proton beam. The most intense line represents $K \alpha_{1,2}$, the second line to the right of $K \alpha_{1,2}$ corresponds to $K \alpha_{3,4}$, while that on the right part of the image is the very faint $K \beta$ line. 


\section{Experimental}

To test the spectrometer performances for the detection of low $\mathrm{Z}$ elements, pure $\mathrm{Mg}, \mathrm{Al}, \mathrm{Si}$ and $\mathrm{S}$ targets were selected. Measurements were performed with a $1 \mathrm{MV}$ Tandetron accelerator at the Ruđer Bošković Institute in Zagreb. A $2 \mathrm{MeV}$ proton beam with a current of $1 \mathrm{nA}$ was used to irradiate samples with a beam spot size of about $10 \times 10 \mu \mathrm{m}^{2} . \mathrm{Mg}$, Al and Si were solid samples while sulphur powder was pelletized to $1 \mathrm{~mm}$ thick pellets of $1 \mathrm{~cm}$ in diameter using a standard press applying a pressure of $6.4 \mathrm{t} \mathrm{cm}^{-2}$. The samples were mounted with carbon tape to a sample holder and placed inside the WD chamber. The CCD chip was cooled down to $-45{ }^{\circ} \mathrm{C}$. $\mathrm{Mg}$ and $\mathrm{Al}$ were measured with the ADP, Si and S with the PET crystal. The energy window seen by the detector depends on the selected crystal and Bragg angle. In the case of $\mathrm{Al}$ and $\mathrm{Si} \mathrm{K}$ lines, it corresponds to $130 \mathrm{eV}$ and $140 \mathrm{eV}$ (respectively) and for $\mathrm{S}$ a somewhat broader energy window of $330 \mathrm{eV}$ is covered. In all the cases that is enough for the simultaneous detection of $\mathrm{K} \alpha$ and $\mathrm{K} \beta$ lines. In the case of $\mathrm{Mg}$, the energy window of $40 \mathrm{eV}$ is not enough to detect both $\mathrm{K} \alpha$ and $\mathrm{K} \beta$ lines separated by $42 \mathrm{eV}$. The available energy window is large enough to observe $\mathrm{K} \alpha$ multiple ionization satellites by heavy ion excitations, which sometimes extend up to the $\mathrm{K} \beta$ region (for proton excitation). Except for $\mathrm{Mg}$, each energy window enables direct comparison of $K \alpha$ and $K \beta$ intensities in a single measurement. Fig. 4 shows the obtained high resolution $\mathrm{K} \alpha \mathrm{Mg}, \mathrm{Al}, \mathrm{Si}$ and $\mathrm{S}$ spectra. The highest intensity peak corresponds to the diagram line with one vacancy in the $\mathrm{K}$ shell. It is an unresolvable doublet $\left(\mathrm{K} \alpha_{1}\right.$ and $\mathrm{K} \alpha_{2}$ originating in $2 \mathrm{p}_{3 / 2} \rightarrow 1$ s and $2 \mathrm{p}_{1 / 2} \rightarrow 1$ s transitions) but in $\mathrm{Al}$ and Si spectra an asymmetry in the peak is visible. $\mathrm{K} \alpha$ satellite peaks can be seen at the high energy side. They are attributed to double ionization processes where the lines involve the same transitions as in the case of diagram lines but in the presence of an additional spectator hole in the $\mathrm{L}$ shell. They are designated as $\mathrm{K} \alpha \mathrm{L}^{i}$ satellites where $i$ marks the number of spectator holes in the $\mathrm{L}$ shell. Although $\mathrm{K} \beta$ lines are also detected in $\mathrm{Al}, \mathrm{Si}$ and $\mathrm{S}$ targets they are not shown in Fig. 4.

All the spectra were fitted with Voigt functions, i.e., convolution of Lorentzian and Gaussian functions describing natural linewidth and instrumental broadening, respectively. A linear background was assumed and subtracted. The final errors in the obtained peak areas were taken from the error estimates of the non-linear least-squares fit parameters and empirical statistical error, which was simply estimated as the square root of the number of counts in the peak. The two errors were added in quadrature. $\mathrm{Mg}$ and $\mathrm{S}$ diagram lines were fitted with one Voigt and $\mathrm{Si}$ and $\mathrm{Al}$ with two Voigt functions. The FWHM obtained is $0.8 \mathrm{eV}$ for $\mathrm{K} \alpha_{1,2}$ of $\mathrm{Mg}$ and $\mathrm{K} \alpha_{1}$ of $\mathrm{Al}$, $1.1 \mathrm{eV}$ for $\mathrm{K} \alpha_{1}$ of $\mathrm{Si}$ and $2.8 \mathrm{eV}$ for $\mathrm{K} \alpha_{1,2}$ of $\mathrm{S}$. The best energy resolution of $E / \Delta E=1850$ was achieved in the case of $\mathrm{Al}$, while for the $S$ region it was 820. $\Delta E$ is based on the experimental spectra and includes natural linewidth and instrumental broadening. In all the cases, the excellent resolution enables the possibility not only to resolve the $\mathrm{K} \alpha \mathrm{L}^{1}$ region from related diagram lines but also to distinguish three components within

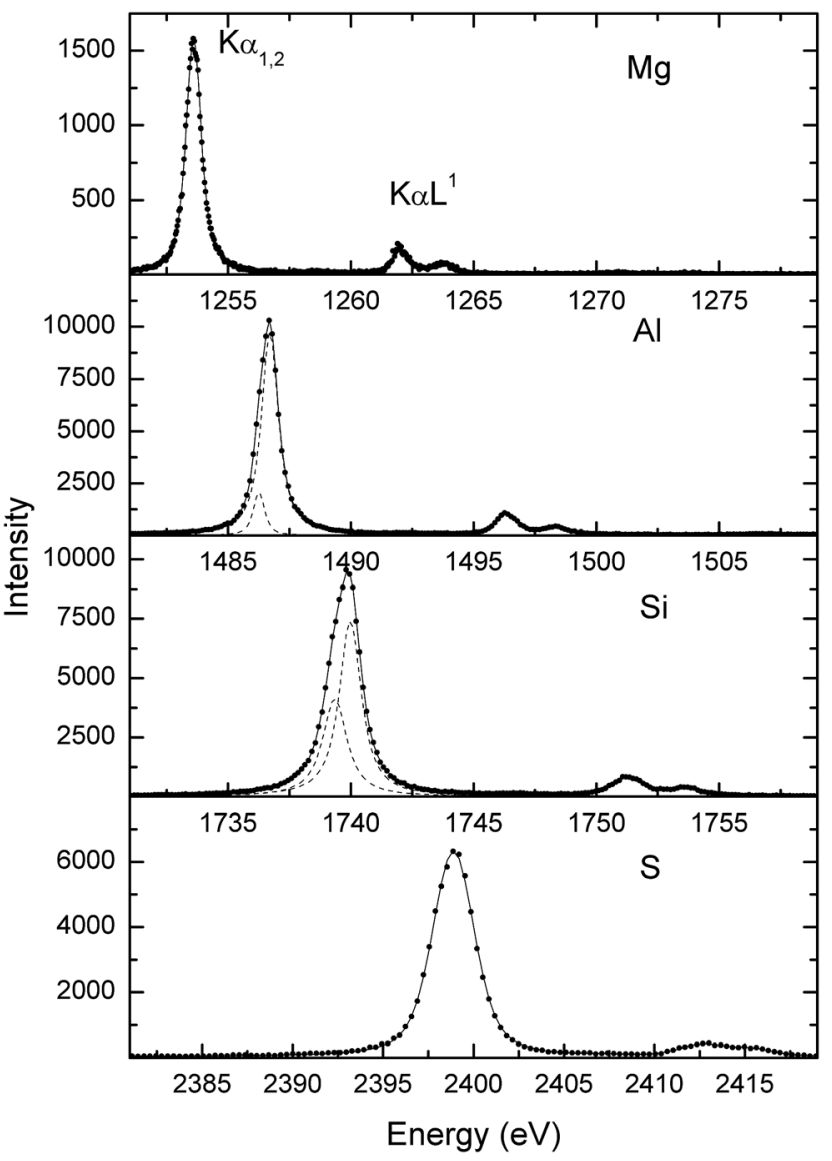

Fig. 4 High resolution $\mathrm{K} \alpha$ emission spectra of $\mathrm{Mg}, \mathrm{Al}, \mathrm{Si}$ and S. They were induced with $2 \mathrm{MeV}$ protons. The crystals used were ADP for Mg and $\mathrm{Al}$, and PET for $\mathrm{Si}$ and $\mathrm{S}$. Dots represent measured and solid lines fitted spectra. In the case of $\mathrm{Al}$ and $\mathrm{Si}, \mathrm{K} \alpha_{1}$ and $K \alpha_{2}$ peak components are shown as dashed lines. The diagram doublet $K \alpha_{1,2}$ and double ionization satellites are marked in the $\mathrm{Mg}$ spectrum.

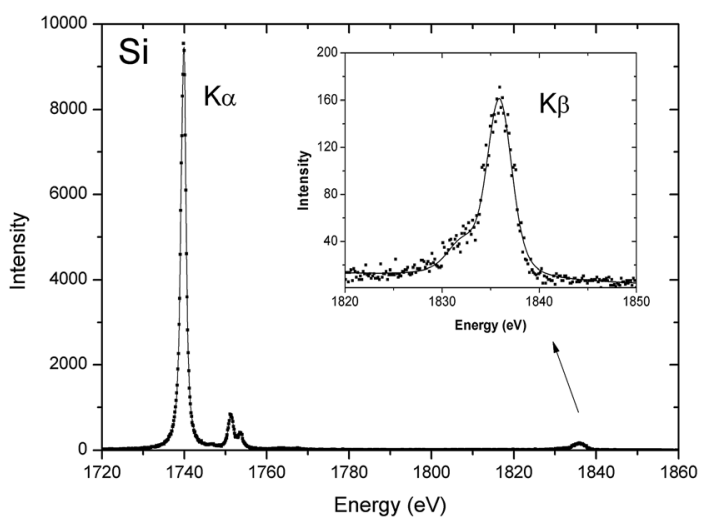

Fig. 5 High resolution $K \alpha$ and $K \beta$ spectrum of silicon induced with 2 $\mathrm{MeV}$ protons. The inserted picture shows an enlarged Si K $\beta$ region. Dots are measured and lines fitted the spectrum.

the $\mathrm{K} \alpha \mathrm{L}^{1}$ region: $\mathrm{K} \alpha^{\prime}, \mathrm{K} \alpha_{3}$ and $\mathrm{K} \alpha_{4}$ (see Fig. 6). The maximum efficiency was obtained for the $\mathrm{Mg}$ target where $220 \mathrm{cps}$ are recorded in the $K \alpha_{1,2}$ peak, while in the case of the Al target it 


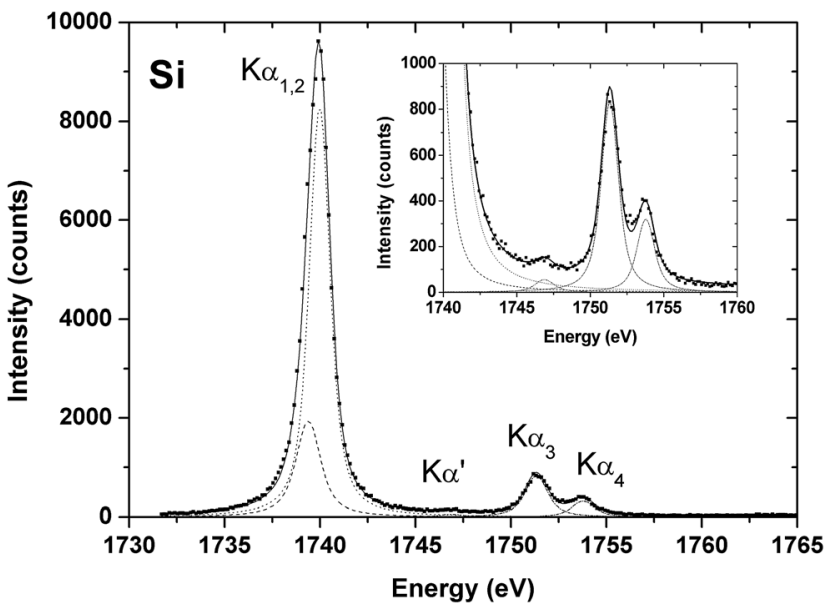

Fig. 6 High resolution Si Ka spectrum induced with $2 \mathrm{MeV}$ protons; dots represent the measured spectrum, full line represents analytical spectrum and dotted lines represent individual Voigt peaks. Inserted figure shows a magnified view of the satellite region.

was $70 \mathrm{cps}$. For silicon and sulphur targets measured with the PET crystal, the sensitivity was 151 and 135 cps in diagram peaks, respectively.

\section{Case study: $\mathrm{Si}$}

2The influence of chemical effects on X-ray emission spectra has been extensively studied to provide information about bonding to the nearest neighbouring atoms. Such studies have been performed after X-ray, electron or ion beam excitation. Most of the studies have been concentrated on the comparison of energy shifts of the diagram or satellite emission lines of a specific element in various compounds, reflecting the change in bond energy in the presence of the neighbouring ligand on Si $\mathrm{K}^{\mathbf{3 0 - 3 4}^{30}}$ and Si K $\beta$ lines..$^{30,35-40}$ Although a majority of studies measured energy shifts, relative intensities of different satellite lines and/or satellite and diagram lines can also be used in chemical speciation avoiding the requirement for WD systems with energy resolutions below $1 \mathrm{eV}$. Fischer and Baun proposed to use the intensity ratio of multiple ionization satellite lines $\alpha_{4}$ and $\alpha_{3}$ as a test of oxidation on metallic targets. ${ }^{3,4}$ Several papers reported relative intensities of the satellite region in silicon and its compounds induced with electrons, ${ }^{4}$ photons ${ }^{41-43}$ and heavy ions. ${ }^{44-46}$ For proton excitation, one detailed study on metallic silicon ${ }^{47}$ was found, although possibilities of chemical speciation based on the change of satellite intensities in proton induced $\mathrm{Si}$ and $\mathrm{SiO}_{2}$ spectra were also proposed., ${ }^{2,48}$

\section{Si K $\alpha$ induced with $2 \mathrm{MeV}$ protons}

The capability of the spectrometer for chemical speciation studies is demonstrated on $\mathrm{K}$ X-rays of silicon and several selected silicon compounds. Silicon, silicon dioxide and silicon carbide targets were solid samples, while sodium metasilicate powder was pelletized in a standard press with the same procedure as that for the sulphur target. The crystal was set to a position matching Bragg angle of $52.5^{\circ}$ for which the energy window seen by the detector is $140 \mathrm{eV}$, allowing simultaneous measurement of silicon $\mathrm{K} \alpha$ and $\mathrm{K} \beta$ lines (Fig. 5). A focused 2 $\mathrm{MeV}$ proton beam was used as an ion probe. The total exposure time for $\mathrm{Si}, \mathrm{SiO}_{2}, \mathrm{SiC}$ and $\mathrm{Na}_{2} \mathrm{SiO}_{3}$ was 14, 20, 30 and 293 minutes, respectively. To eliminate the visible IBIL signal, $5 \mu \mathrm{m}$ thin aluminized Mylar was placed on $\mathrm{SiO}_{2}$ and $\mathrm{SiC}$ targets while $25 \mu \mathrm{m}$ beryllium was mounted on $\mathrm{Na}_{2} \mathrm{SiO}_{3}$. Each recorded signal image was run through the image processing routine to obtain the final two-dimensional picture. Due to the curvature of the lines, a correction was performed in order to project the spectra to the horizontal axis, as explained in subsection Data acquisition and signal processing.

Fig. 5 shows the final high resolution $K \alpha$ and $K \beta$ spectrum of silicon. The inserted picture shows an enlarged Si K $\beta$ region. Linear energy calibration was done using two reference lines: $\mathrm{K} \alpha_{1} 1739.98 \mathrm{eV}$ and $\mathrm{K} \beta 1835.9 \mathrm{eV} .^{49}$ Due to the closeness of the target and the detector, even small misalignments in target positioning can result in a small line shift in the final spectra that can be misplaced and attributed to chemical shifts. Therefore, we decided to compare only relative distances between X-ray lines of different compounds. $K \alpha_{1}$ lines in the spectra related to the measured Si compounds have been all aligned to the position of the Si target spectrum. Fig. 6 shows the $\mathrm{Si} K \alpha$ region with the most intense diagram $\mathrm{K} \alpha_{1,2}$ line and the inserted picture of the $\mathrm{K} \alpha \mathrm{L}^{1}$ region, where three satellite lines are resolved. Fitting of the diagram lines was performed with two Voigt functions and the satellite region with 3: $K \alpha^{\prime}$, $\mathrm{K} \alpha_{3}, \mathrm{~K} \alpha_{4}$. The full width at half maximum (FWHM) of the Si $\mathrm{K} \alpha_{1}$ profile was $1.1 \mathrm{eV}$ which was good enough to resolve $\mathrm{K} \alpha_{3}$ and $\mathrm{K} \alpha_{4}$ satellites which are $2.3 \mathrm{eV}$ apart. The relative intensities of $\mathrm{K} \alpha \mathrm{L}^{1}$ components for silicon and its compounds: $\mathrm{I}_{\mathrm{r}}\left(\mathrm{K} \alpha^{\prime}\right), \mathrm{I}_{\mathrm{r}}\left(\mathrm{K} \alpha_{3}\right)$ and $\mathrm{I}_{\mathrm{r}}\left(\mathrm{K} \alpha_{4}\right)$ are listed in Table 1 . Also ratios of $K \alpha_{3}$ and $K \alpha_{4}$ lines together with ratios of total intensity of $K \alpha \mathrm{L}^{1}$ relative to $\mathrm{K} \alpha \mathrm{L}^{0}$ are shown. The obtained values for silicon are compared with the

Table 1 Intensities of $K \alpha^{\prime}, K \alpha_{3}$ and $K \alpha_{4}$ lines relative to $K \alpha L^{1}$ total intensity, intensity ratio of $K \alpha_{3}$ and $K \alpha_{4}$ lines, intensity ratio of $K \alpha L^{1}$ and $K \alpha L^{0}$ for $S i$, $\mathrm{SiO}_{2}, \mathrm{SiC}$ and $\mathrm{Na}_{2} \mathrm{SiO}_{3}$. Intensities are corrected for absorption in foils on the target and the detector. Our values are compared to the values obtained for silicon induced with $2 \mathrm{MeV}$ protons reported by Kavčič. ${ }^{47}$

\begin{tabular}{|c|c|c|c|c|c|}
\hline & $\mathrm{Si}$ & $\mathrm{Si}^{47}$ & $\mathrm{SiO}_{2}$ & $\mathrm{SiC}$ & $\mathrm{Na}_{2} \mathrm{SiO}_{3}$ \\
\hline $\mathrm{I}_{\mathrm{r}}\left(\mathrm{K} \alpha^{\prime}\right)(\%)$ & $4 \pm 1$ & $3.6 \pm 0.3$ & $5 \pm 1$ & $5 \pm 1$ & $4 \pm 2$ \\
\hline $\mathrm{I}_{\mathrm{r}}\left(\mathrm{K} \alpha_{3}\right)(\%)$ & $71 \pm 3$ & $67.1 \pm 0.9$ & $63 \pm 3$ & $65 \pm 2$ & $60 \pm 6$ \\
\hline $\mathrm{I}\left(\mathrm{K} \alpha_{3}\right) / \mathrm{I}\left(\mathrm{K} \alpha_{4}\right)$ & $2.8 \pm 0.2$ & $2.29 \pm 0.07$ & $2.0 \pm 0.2$ & $2.2 \pm 0.1$ & $1.6 \pm 0.2$ \\
\hline $\mathrm{I}\left(\mathrm{K} \alpha \mathrm{L}^{1}\right) / \mathrm{I}\left(\mathrm{K} \alpha \mathrm{L}^{0}\right)(\%)$ & $12.8 \pm 0.5$ & $13.2 \pm 0.7$ & $14.5 \pm 0.7$ & $14.7 \pm 0.4$ & $19 \pm 1$ \\
\hline
\end{tabular}


ones from Kavčič who also used excitation with 1, 2 and $3 \mathrm{MeV}$ protons. ${ }^{47} \mathrm{I}\left(\mathrm{K} \alpha_{3}\right) / \mathrm{I}\left(K \alpha_{4}\right)$ and $\mathrm{I}\left(\mathrm{K} \alpha \mathrm{L}^{1}\right) / \mathrm{I}\left(\mathrm{K} \alpha \mathrm{L}^{0}\right)$ vary for different silicon compounds and have potential to be used for chemical speciation. From measurements on three different proton energies on pure silicon, it was noticed that the intensity ratio of $\mathrm{K} \alpha \mathrm{L}^{1}$ relative to $\mathrm{K} \alpha \mathrm{L}^{0}$ decreases from $18.6 \%$ to $8.5 \%$ while increasing the proton energy from 1 to $3 \mathrm{MeV} .{ }^{47}$ The same trend is observed in $\mathrm{I}\left(\mathrm{K} \alpha_{3}\right) / \mathrm{I}\left(\mathrm{K} \alpha_{4}\right)$ but the change in ratio is less than $10 \%$.

Fig. 7 shows the $\mathrm{K} \alpha$ satellite region for $\mathrm{Si}, \mathrm{SiO}_{2}, \mathrm{SiC}$ and $\mathrm{Na}_{2} \mathrm{SiO}_{3}$. Variation in $\mathrm{K}_{3}$ and $\mathrm{K} \alpha_{4}$ intensities for different $\mathrm{Si}$ compounds is clearly visible. Previous studies reported that chemical shifts in $K \alpha$ lines are directly related to effective charges on the Si atom. ${ }^{33,34}$ An increase of the effective number of electrons in the valence shell of the central atom in the presence of electronegative neighbouring atoms will cause stronger bonding of the inner shell electrons, shifting the $K \alpha_{1,2}$ line to higher energies. To test if the intensity ratio of $K \alpha_{3}$ and $\mathrm{K} \alpha_{4}$ lines and the ratio of $\mathrm{K} \alpha \mathrm{L}^{1}$ to $\mathrm{K} \alpha \mathrm{L}^{0}$ are sensitive to the chemical environment, variation of these intensity ratios with effective charge on $\mathrm{Si}$ is shown in Fig. 8 and 9. Values for effective charges on $\mathrm{Si}$ in $\mathrm{SiC}$ and $\mathrm{SiO}_{2}$ were obtained from ref.

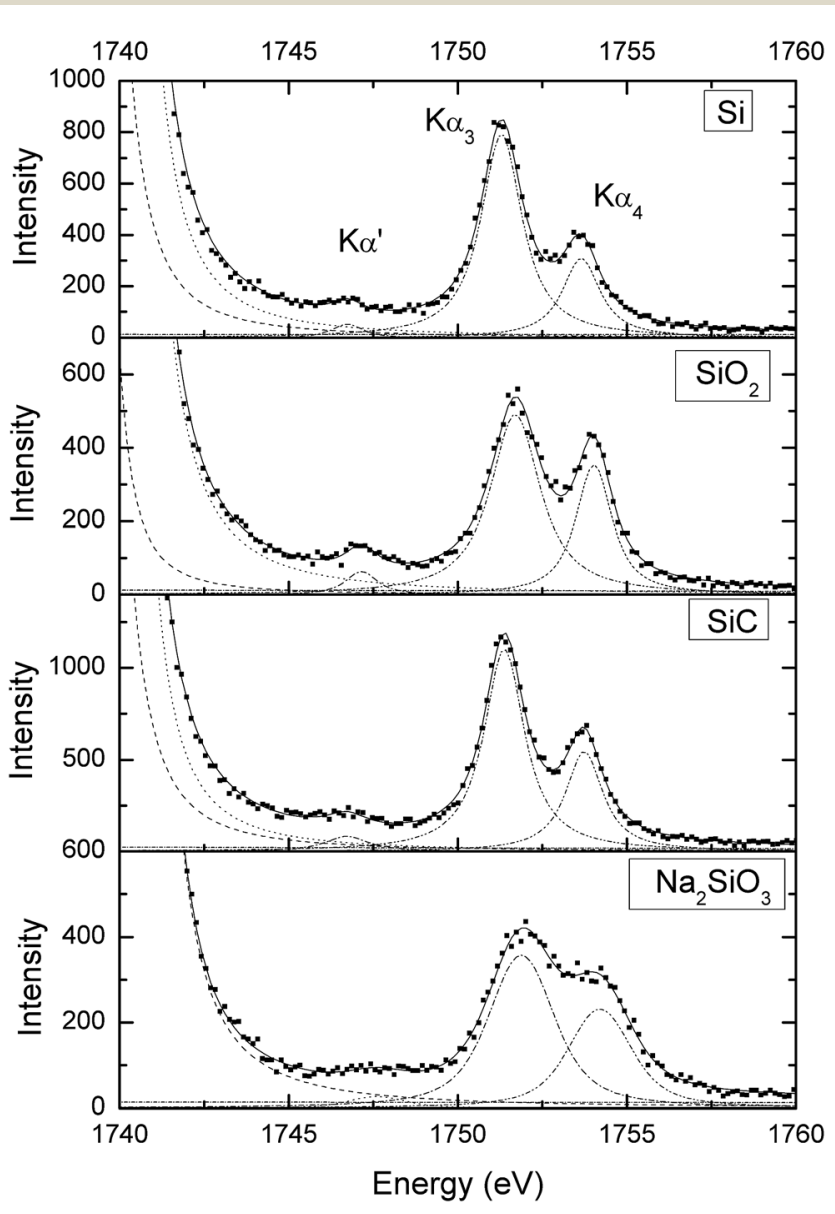

Fig. 7 The Si K $\alpha \mathrm{L}^{1} \mathrm{X}$-ray spectra of silicon and its compounds induced with $2 \mathrm{MeV}$ protons. Dots represent experimental data, the solid line represents fitted spectra while the dotted line represents individual Voigt functions. Compound spectra are aligned relative to the $K \alpha_{1}$ line of pure silicon.

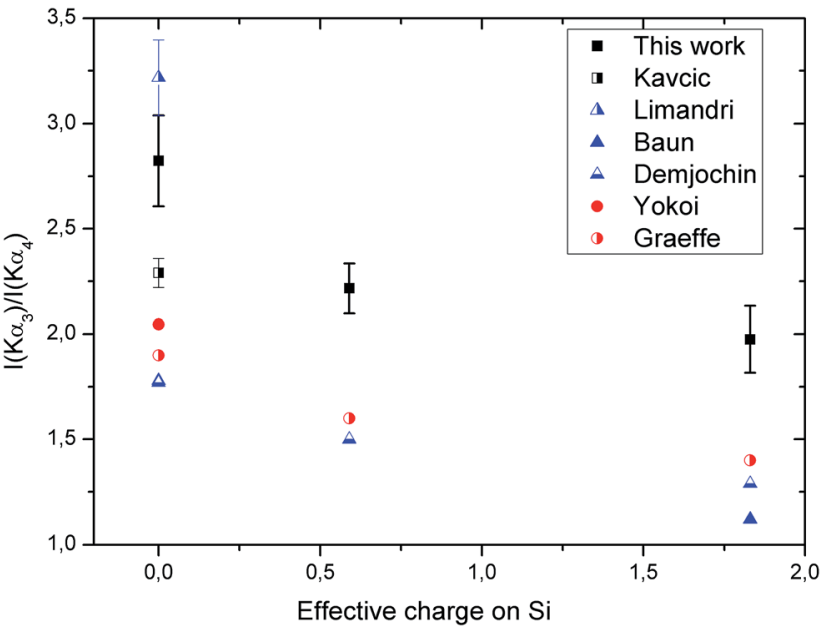

Fig. 8 Variation of $K \alpha_{3}$ and $K \alpha_{4}$ intensity ratios with effective charge on Si. Colours represent different excitation methods: black squares for protons (filled squares: present work, vertically filled squares ${ }^{47}$ ), blue triangles for electrons (filled triangles ${ }^{4}$, vertically filled triangles ${ }^{51}$, horizontally filled ${ }^{52}$ ) and red circles for photons (filled ${ }^{50}$, vertically filled ${ }^{41}$.

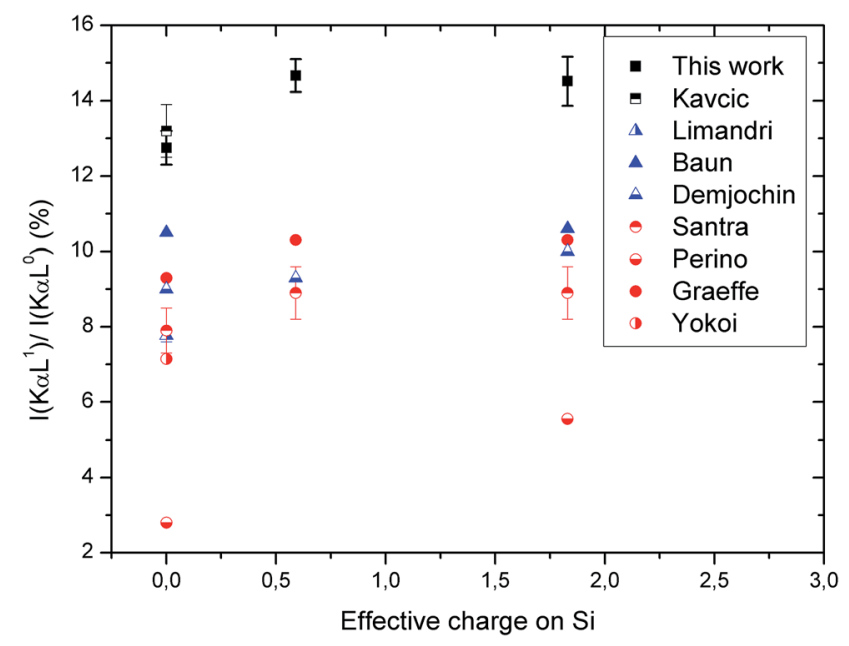

Fig. 9 Variation of $K \alpha L^{1}$ and $K \alpha L^{0}$ intensity ratios with effective charge on $\mathrm{Si}$. Colours represent different excitation methods: black squares for protons (filled squares: present work, horizontally filled squares ${ }^{47}$ ), blue triangles for electrons (filled triangles ${ }^{4}$, vertically filled triangles ${ }^{51}$, horizontally filled ${ }^{52}$ ) and red circles for photons (filled ${ }^{41}$, vertically filled ${ }^{50}$, horizontally filled ${ }^{42,43}$ ).

33 where they were calculated with the DV-X $\alpha$ molecular orbital method and compared to other calculations. ${ }^{34}$ For pure silicon, zero effective charge was assumed. The values of 1.83 and 0.59 were taken for $\mathrm{SiO}_{2}$ and $\mathrm{SiC}$. Our experimental values are compared to the reported values obtained using photons, ${ }^{41-43,50}$ electrons ${ }^{\mathbf{4 , 4 1 , 5 2}}$ and energetic protons as excitation sources. ${ }^{47}$ A clear offset between the curves is seen between different excitation methods, where the highest $K \alpha_{3}$ to $\mathrm{K}_{4}$ intensity ratio is for proton excitation and the lowest one for electrons. Also, the highest $\mathrm{K} \mathrm{L}^{1} / \mathrm{K} \alpha \mathrm{L}^{0}$ intensity ratios are for proton excitations. 


\section{Si K $\beta$ induced with $2 \mathrm{MeV}$ protons}

The $K \beta$ region is more sensitive to the chemical environment of the central atom. In this study silicon $K \beta$ lines were measured simultaneously with $\mathrm{K} \alpha$ lines. The measured $\mathrm{K} \beta$ part of the spectra is shown in Fig. 10. As already explained, the compound spectra are aligned relative to the $K \alpha_{1}$ line of pure silicon, so shifts in the diagram $K \beta_{1,3}$ line are relative. The most intense peak in all the spectra corresponds to the $K \beta_{1,3}$ diagram line and the broad structure on the low energy side is attributed to the broad radiative Auger effect (RAE). This effect appears when the emission of photons is accompanied by an ejection of another outer shell electron, reducing the energy of the related diagram line. A detailed study of different contributions to the K $\beta$ RAE structure of pure silicon by the electron impact can be found in the report by Limandri et al. ${ }^{53}$ On the low energy side of silicon compound $K \beta$ spectra, an additional $\mathrm{K} \beta^{\prime}$ peak can be distinguished. In compounds, the $\mathrm{K} \beta_{1,3}$ line originates in the transition from a molecular orbital formed from Si $3 p$ and ligand $2 p$ orbitals, while $K \beta^{\prime}$ is related to the transition from Si $3 p$ and ligand $2 \mathrm{~s}$ orbitals. Therefore, the energy difference between $K \beta_{1,3}$ and $K \beta^{\prime}$ lines approximately corresponds to the energy difference in ligand $2 \mathrm{p}$ and $2 \mathrm{~s}$

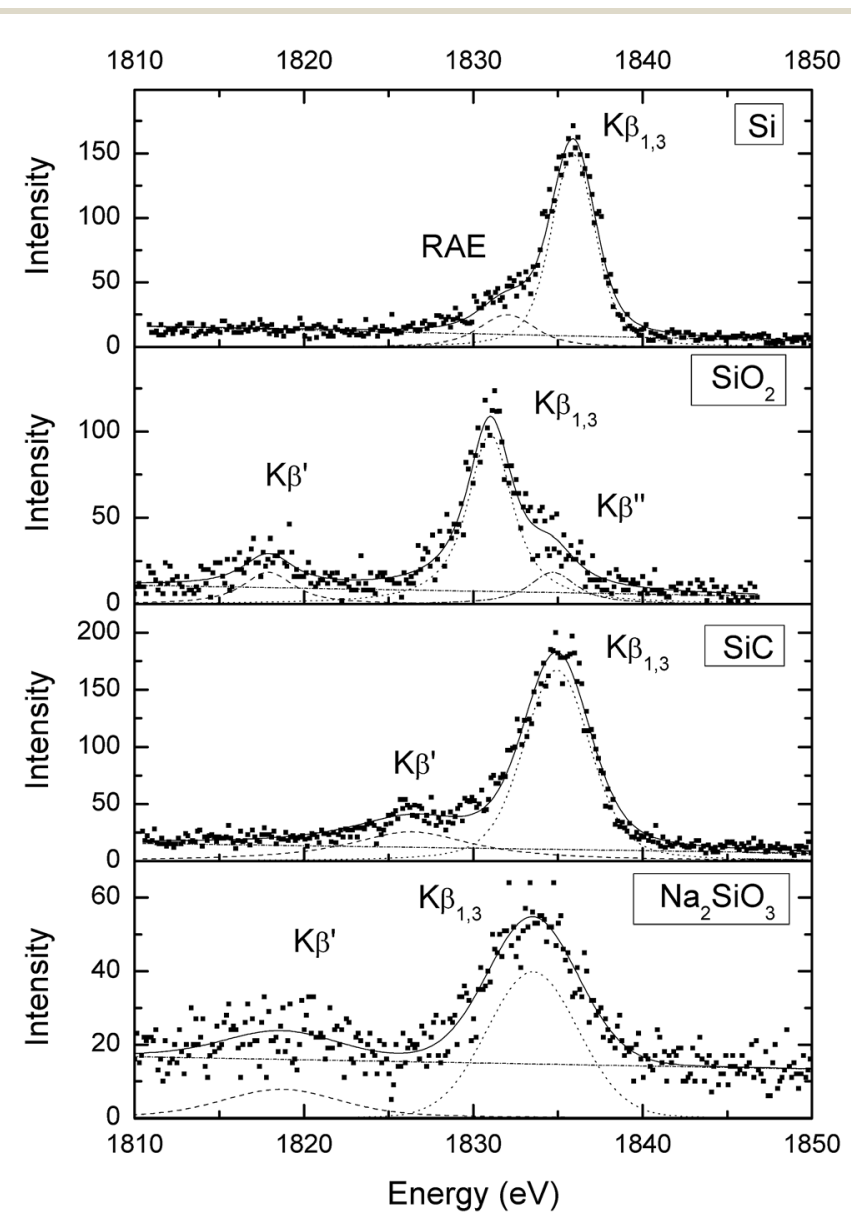

Fig. 10 High resolution $K \beta$ spectra of $\mathrm{Si}, \mathrm{SiO}_{2}, \mathrm{SiC}$ and $\mathrm{Na}_{2} \mathrm{SiO}_{3}$ induced with $2 \mathrm{MeV}$ protons; dots represent the measured spectrum, full lines represent the analytical spectrum and dotted lines represent individual Voigt functions. ionisation energies. Since the energy difference increases with the ligand atomic number, going from $5.4 \mathrm{eV}$ for $\mathrm{C}$ up to $20.4 \mathrm{eV}$ for $\mathrm{F}$, measurements of $\left(\mathrm{E}\left(\mathrm{K} \beta_{1,3}\right)-\mathrm{E}\left(\mathrm{K} \beta^{\prime}\right)\right)$ can be used for light element detection in targets even if two different types of ligands are present in the sample. ${ }^{54}$ In our case the observed energy difference for $\mathrm{SiO}_{2}, \mathrm{SiC}$ and $\mathrm{Na}_{2} \mathrm{SiO}_{3}$ was $13.1 \pm 0.5 \mathrm{eV}$, $8.6 \pm 0.5 \mathrm{eV}$ and $14.9 \pm 0.7 \mathrm{eV}$ which are close to the values obtained by other authors. ${ }^{33,43,54}$ The intensity of the $\mathrm{K} \beta^{\prime}$ peak was $15 \%$ for $\mathrm{SiO}_{2}, 23 \%$ for $\mathrm{Na}_{2} \mathrm{SiO}_{3}$ and $28 \%$ of total $\mathrm{K} \beta$ intensity in the case of SiC. An additional line designated as $\mathrm{K} \beta^{\prime \prime}$ appears at $3.7 \pm 0.6 \mathrm{eV}$ above the $\mathrm{K} \beta_{1,3}$ line in the $\mathrm{SiO}_{2}$ spectrum. Its relative intensity of $11 \%$ is similar to the value published by Takahashi. ${ }^{55}$ A detailed discussion about its origin can be found in several papers, but further theoretical calculations are needed. ${ }^{56,57}$ The $\mathrm{K} \beta$ region of $\mathrm{Na}_{2} \mathrm{SiO}_{3}$ shows a similar structure to that of $\mathrm{SiO}_{2}$ but its fine structure is unresolvable. $\mathrm{K} \beta$ emission lines offer many more opportunities for chemical speciation studies but their substantially lower intensity compared to $K \alpha$ lines (intensity ratio of $K \beta$ and $\mathrm{K} \alpha$ is $2.4 \%$ for silicon ${ }^{58}$ ) presents an obstacle.

\section{Si K $\alpha$ induced with $20 \mathrm{MeV}$ carbon ions}

It has been known from numerous studies that in heavy ion collisions, the probability for multiple ionization is enhanced, leaving target atoms in states with multiple additional vacancies in $\mathrm{L}$ and outer shells. As a result, the intensity pattern of the $\mathrm{K} \alpha$ satellite region substantially changes when compared to its distribution in the case of photon, electron or proton excitation. Each additional hole in the $\mathrm{L}$ shell will shift the emitted $\mathrm{K} \alpha$ $\mathrm{X}$-ray line to higher energy. Such energy shifts are in the order of around $10 \mathrm{eV}$ per additional hole in the L shell. Although the influence of multiple ionizations induced by heavy ions can be studied by ordinary ED spectrometers, ${ }^{59}$ high resolution spectrometers are mandatory to clearly resolve individual $\mathrm{K}_{\alpha} \mathrm{L}^{i}$ satellites, where $i$ represents the number of vacancies in the $\mathrm{L}$ shell. Individual peaks within the specific $\mathrm{K} \alpha \mathrm{L}^{i}$ satellite can be resolved depending on spectrometer performances but limits are set with spin-orbit coupling of electron angular momenta and smearing of lines by the presence of spectator holes in outer shells. Directly from the X-ray satellite intensity, the apparent average $\mathrm{L}$ vacancy fraction in the moment of X-ray emission can be calculated according to the formula:

$$
p_{\mathrm{L}}{ }^{x}=\frac{1}{8} \sum_{i=1}^{8} \frac{i I_{i}}{I_{\mathrm{tot}}}
$$

where $I_{i}$ represents the intensity of the satellite group with $i$ vacancies in the $\mathrm{L}$ shell and

$$
I_{\mathrm{tot}}=\sum_{i=0}^{8} I_{i}
$$

is the total intensity of the K $\alpha$ diagram and satellite lines. Some of the authors used binomial probability distribution

$$
I_{i}=I_{\mathrm{tot}}\left(\begin{array}{c}
8 \\
i
\end{array}\right)\left(p_{\mathrm{L}}{ }^{x}\right)^{i}\left(1-p_{\mathrm{L}}{ }^{x}\right)^{8-i}
$$


to describe the relative intensity distribution of $\mathrm{K} \alpha$ satellites, which is based on the assumption of independent production of $\mathrm{L}$ shell vacancies.

Interpretation of $p_{\mathrm{L}}{ }^{x}$ is not straightforward since the $\mathrm{L}$ vacancy distribution differs in the moment of the X-ray emission from the distribution after heavy ion collision. To extract the true value of $L$ vacancy distribution in the moment of a heavy ion collision, a few corrections are needed: (i) correction for vacancy rearrangement where L shell holes created after ion collision can be filled from outer shells and (ii) fluorescence yield corrections due to the fact that its values differ for different $\mathrm{K}_{\alpha} \mathrm{L}^{i}$ satellites. However, $p_{\mathrm{L}}{ }^{x}$ values represent a good parameter for comparison since they are obtained directly from measurements with no need to use model based corrections. ${ }^{60}$ Higher $p_{\mathrm{L}}{ }^{x}$ values imply a shift of intensity distribution to an increased number of L shell vacancies and vice versa. Detailed studies with different projectile-target combinations can reveal the origin of $\mathrm{L}$ shell vacancy production and processes of $\mathrm{L}$ shell rearrangements after the collision. Some studies related to $2 \mathrm{~d}$ and $3 \mathrm{~d}$ elements show the variation of relative intensities and energy shifts of $\mathrm{K} \alpha \mathrm{L}^{i}$ satellites between different compounds. Explanation for this different distribution lies in the L vacancy transfer from intra-atomic transitions from higher shells of the same atom and interatomic transitions from neighbouring

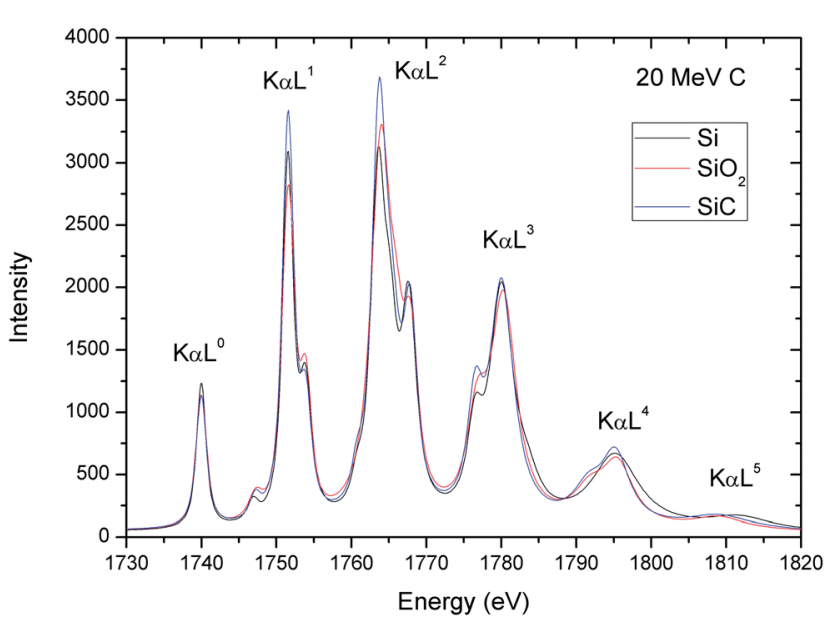

Fig. $11 \mathrm{Si} \mathrm{K \alpha} \mathrm{X-ray} \mathrm{intensity} \mathrm{distribution} \mathrm{for} \mathrm{Si}, \mathrm{SiO}_{2}$ and $\mathrm{SiC}$ targets induced with $20 \mathrm{MeV}$ carbon ions. Correction for absorption in foils on

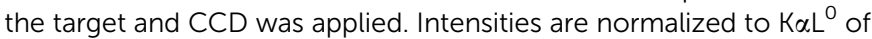
pure silicon. atoms following heavy ion collisions. ${ }^{16}$ The decrease of $p_{\mathrm{L}}{ }^{x}$ values with the increase of average valence electron density for several aluminium, silicon, sulphur and chlorine compounds, ${ }^{\mathbf{1 6 , 6 1}}$ supported by additional measurements on gaseous samples, ${ }^{\mathbf{4 6}}$ further revealed the importance of chemical bonding in the transfer of vacancies from valence levels of ligand atoms. In atoms with lower effective charges, valence electrons are more bound to the central atom. In collision with heavy ions there is a greater probability that they are ejected compared to atoms with a higher effective charge, where most of the valence electrons are shifted toward neighbouring atoms. So for higher effective charge compounds more valence electrons are at a disposal to transfer to $\mathrm{L}$ shell vacancies created after ion collision. This rearrangement of L shell holes leads to the reduction of $\mathrm{L}$ shell holes shifting the relative intensity distribution to lower ${p_{\mathrm{L}}}^{x}$ values. ${ }^{46,62}$

The goal of our experiment was to test the capability of our spectrometer for chemical speciation with heavy ions on silicon compounds. Measurements were performed with $20 \mathrm{MeV}$ (i.e. 1.67 MeV/amu) carbon ions from a Tandem Van der Graaff accelerator. The spectrometer setup was the same as in the experiment with $2 \mathrm{MeV}$ protons. The ion beam current on the target was around $1 \mathrm{nA}$. Fig. 11 shows the high resolution $\mathrm{K} \alpha$ X-ray spectra of $\mathrm{Si}$ in pure $\mathrm{Si}, \mathrm{SiO}_{2}$ and $\mathrm{SiC}$. For the ease of comparison, the compound spectra are normalized to the total intensity of ${\mathrm{K} \alpha \mathrm{L}^{0}}^{0}$ lines of pure silicon, with aligned positions of the $\mathrm{K} \alpha \mathrm{L}^{0}$ line. Besides the ability to separate each $\mathrm{K} \alpha \mathrm{L}^{i}$ group of satellites, individual components within a specific $\mathrm{K} \alpha \mathrm{L}^{i}$ group are also resolved, showing the fine structure of the $\mathrm{K} \alpha$ satellite region. The obtained resolution of $1.7 \mathrm{eV} F W H M$ for $\mathrm{K} \alpha \mathrm{L}^{0}$ in pure silicon is much better than $7 \mathrm{eV}$ that was reported in some of the earlier studies on chemical speciation with heavy ions using broad ion beams. ${ }^{16}$ This resolution allows for the fine structure to be resolved in individual multiple ionization $\mathrm{Si} \mathrm{K \alpha}$ X-ray satellite lines. As can be seen from Fig. 11, the fine structures of $\mathrm{K} \mathrm{L}^{1}, \mathrm{~K} \alpha \mathrm{L}^{2}$ and $\mathrm{K} \alpha \mathrm{L}^{3}$ components show clear changes in relative intensities between $\mathrm{Si}, \mathrm{SiO}_{2}$ and $\mathrm{SiC}$. Table 2 shows relative satellite intensities $\left(I_{i} / I_{\text {tot }}\right)$ resulting from fitting of the spectra following the same procedure used to fit the spectra obtained with proton excitation. The intensity ratios are corrected for absorption in foils on the target and on the detector.

$p_{\mathrm{L}}{ }^{x}$ values are calculated according to formula (1) and compared to the values obtained by Watson et al. ${ }^{16}$ They used 22 $\mathrm{MeV}$ (i.e. $1.83 \mathrm{MeV} / \mathrm{amu}$ ) C ions, $5.4 \mathrm{MeV}$ (i.e. $1.36 \mathrm{MeV} / \mathrm{amu}) \mathrm{He}$

Table 2 Relative $I_{i} / I_{\text {tot }}$ intensities and $p_{\mathrm{L}}{ }^{x}$ values obtained with $20 \mathrm{MeV} \mathrm{C}$ (this work), comparison with $p_{\mathrm{L}}{ }^{x}$ values obtained with $22 \mathrm{MeV} \mathrm{C}$ and 32.4 $\mathrm{MeV} \mathrm{O}^{16}$

\begin{tabular}{llllllllll}
\hline & $I_{i} / I_{\text {tot }}$ & & & & & & & \\
\cline { 2 - 5 } Compound & $i=0$ & $i=1$ & $i=2$ & $i=3$ & $i=4$ & $i=5$ & $p_{\mathrm{L}}{ }^{x} 20 \mathrm{MeV}$ C (this work) & $p_{\mathrm{L}}{ }^{x} 22 \mathrm{MeV} \mathrm{C}^{16}$ & $p_{\mathrm{L}}{ }^{x} 32.4 \mathrm{MeV} \mathrm{O}^{16}$ \\
\hline $\mathrm{Si}$ & 0.047 & 0.194 & 0.339 & 0.258 & 0.130 & 0.032 & $0.291 \pm 0.005$ & 0.267 & 0.348 \\
$\mathrm{SiO}_{2}$ & 0.046 & 0.193 & 0.378 & 0.261 & 0.100 & 0.023 & $0.280 \pm 0.006$ & 0.258 & 0.317 \\
$\mathrm{SiC}$ & 0.046 & 0.201 & 0.361 & 0.254 & 0.103 & 0.035 & $0.284 \pm 0.005$ & 0.322
\end{tabular}


ions and $32.4 \mathrm{MeV}$ (i.e. $2 \mathrm{MeV} / \mathrm{amu}$ ) O ions. $p_{\mathrm{L}}{ }^{x}$ values increase, i.e. L-shell vacancy distribution shifts to higher multiple ionization states, going from lower to higher $\mathrm{Z}$ ions (Fig. 12). This is in agreement with previously obtained results, where $p_{\mathrm{L}}{ }^{x}$ values increase with the projectile atomic number until the saturation point is reached when the atomic number of the projectile is close to the one of the target. ${ }^{15}$

Fig. 13 shows the variation of $p_{\mathrm{L}}{ }^{x}$ values with the effective charge on the Si atom. A decrease of $p_{\mathrm{L}}{ }^{x}$ with increasing effective charge on silicon can be observed, although the effect is not so pronounced and variation between the values is small for $\mathrm{C}$ ions with an energy of about $2 \mathrm{MeV} / \mathrm{amu}$. For He ions only $\mathrm{K}_{\alpha} \mathrm{L}^{1}$ and $\mathrm{K} \alpha \mathrm{L}^{2}$ satellites are observed and the variation of $p_{\mathrm{L}}{ }^{x}$ between different Si compounds is within experimental error, making $p_{\mathrm{L}}{ }^{x}$ values insensitive to chemical speciation. Contrary to $\mathrm{He}$ and $\mathrm{C}$ ions, the variation of ${p_{\mathrm{L}}}^{x}$ values for $32.4 \mathrm{MeV} \mathrm{O}$ ions among different silicon compounds is much higher, attributed to their higher $p_{\mathrm{L}}{ }^{x}$. We can conclude that for silicon chemical

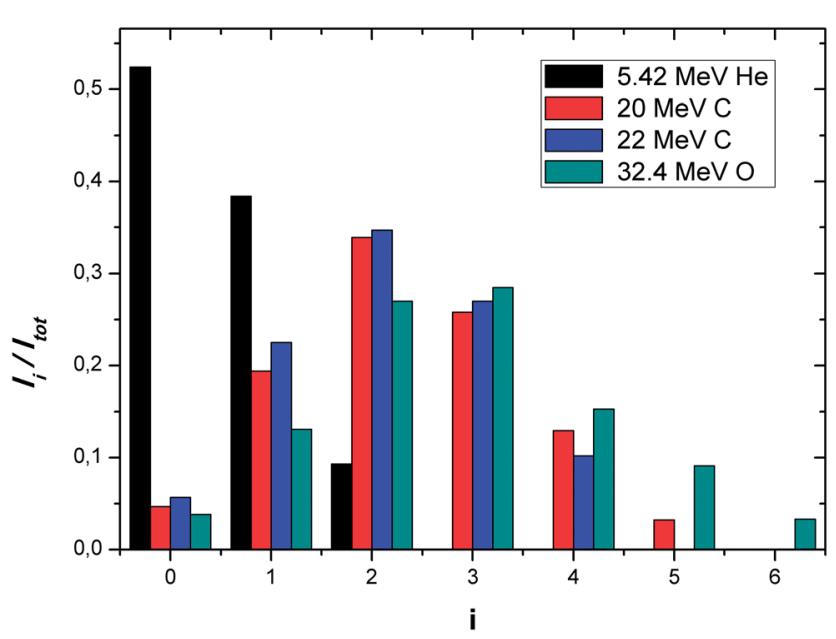

Fig. 12 Relative intensity distribution of $\mathrm{K} \mathrm{L}^{i}$ satellites for pure silicon with $5.42 \mathrm{MeV} \mathrm{He},{ }^{16} 20 \mathrm{MeV} \mathrm{C}$ (this work), $22 \mathrm{MeV} \mathrm{C}^{16}$ and $32.4 \mathrm{MeV} \mathrm{O}$ ions. $^{16}$

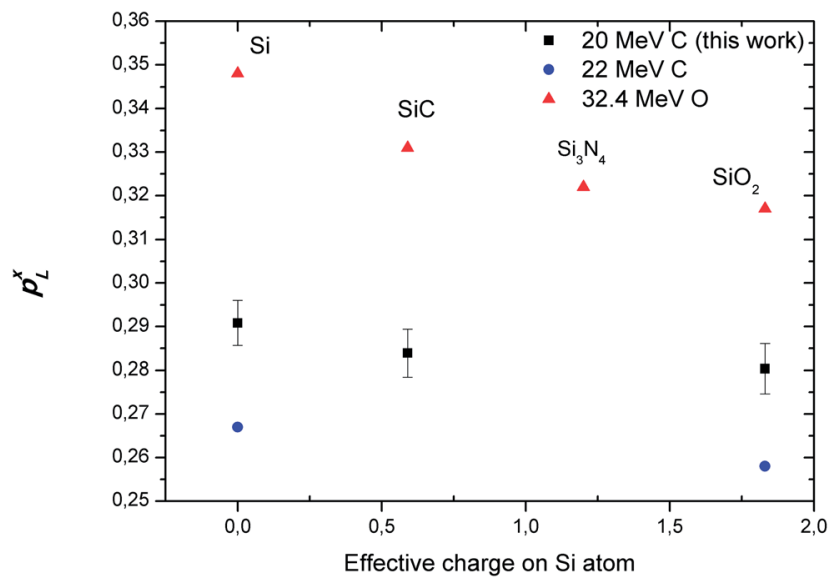

Fig. 13 Dependence of $p_{\mathrm{L}}{ }^{x}$ values with effective charge on silicon excited with $20 \mathrm{MeV} C$ (this work), $22 \mathrm{MeV} \mathrm{C}{ }^{16}$ and $32.4 \mathrm{MeV} \mathrm{O}{ }^{16}$

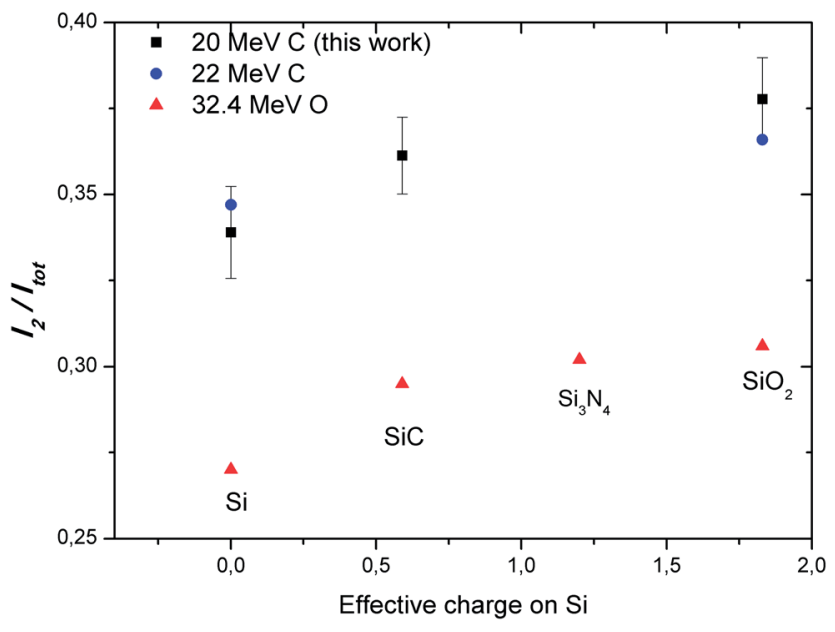

Fig. 14 Variation of relative $I_{2} / I_{\text {tot }}$ intensity with effective charge on the Si atom for $20 \mathrm{MeV} C$ (this work), $22 \mathrm{MeV} \mathrm{C}$ and $32.4 \mathrm{MeV} \mathrm{O.}{ }^{16}$

speciation studies based on $p_{\mathrm{L}}{ }^{x}$ values in the range of energies around $2 \mathrm{MeV} / \mathrm{amu}$, ions heavier than carbon, i.e. those with the atomic number close to silicon should be selected.

Fig. 11 suggests that relative $\mathrm{K} \mathrm{L}^{1}$ and $\mathrm{K} \alpha \mathrm{L}^{2}$ relative intensities have larger differences between different compounds. In their study of sulphur compounds with $\mathrm{Ar}$ and $\mathrm{Kr}$ ions, Vane et al. ${ }^{63}$ found a correlation between the relative $\mathrm{K} \alpha \mathrm{L}^{2}$ intensity and effective charge on the $\mathrm{S}$ atom and the relative intensity of $\mathrm{K} \alpha \mathrm{L}^{5}$ with the average valence-electron density of $\mathrm{S}$ compounds. Fig. 14 shows the variation of relative intensity $I_{2} / I_{\text {tot }}$ with effective charge on the Si atom obtained from our spectra from silicon and its selected compounds. The figure also shows the values obtained by Watson et al. for $20 \mathrm{MeV} \mathrm{C}$ and $32.4 \mathrm{MeV} \mathrm{O}$ ions. ${ }^{16}$ It seems that for excitation with $20 \mathrm{MeV}$ carbon ions, relative $\mathrm{K} \alpha \mathrm{L}^{2}$ intensities show larger variations with the effective charge on the Si atom than the variation of $p_{\mathrm{L}}{ }^{x}$ values do.

\section{Conclusions}

We have designed and developed a downsized WD X-ray spectrometer for use with focused ion beams, based on a plane crystal geometry and a Peltier cooled pixelized detector with excellent spatial resolution. Although it covers the X-ray energy range between 1.2 and $8.4 \mathrm{keV}$, the system is optimised for the $\mathrm{K}$ $\mathrm{X}$-ray energy range of light elements ( $\mathrm{Al}$ to $\mathrm{Cl}$ ). An energy resolution of $1.1 \mathrm{eV}(\mathrm{FWHM})$ for $\mathrm{Si} \mathrm{K}_{1}$ under $2 \mathrm{MeV}$ proton excitation enabled clear separation of three $\mathrm{K} \alpha \mathrm{L}^{1}$ satellite components while the energy window of $130 \mathrm{eV}$ for the Si K region ensures simultaneous detection of $K \alpha$ and $K \beta$ lines which is of great advantage in detecting multiple ionization satellites in a single measurement.

In this work we employed the spectrometer to study ion beam induced chemical effects in Si K X-ray spectra from silicon and some selected compounds induced by focused $2 \mathrm{MeV}$ protons and $20 \mathrm{MeV}$ carbon ions. We particularly analysed the intensity ratios of silicon $\mathrm{K}_{3}$ to $\mathrm{K} \alpha_{4}$ satellite lines and of $\mathrm{K} \alpha \mathrm{L}^{1}$ satellites to $\mathrm{K} \alpha \mathrm{L}^{0}$ diagram lines induced by $2 \mathrm{MeV}$ protons. Both 
ratios showed variations with effective charge on silicon. A clear distinction between different excitation methods was observed

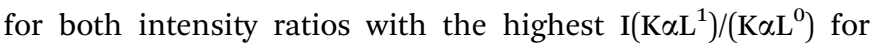
proton excitation as a direct signature of higher multiple ionization probability for protons compared to electron and photon excitation.

It is known that interaction with heavy MeV energy ions considerably increases the probability for multiple ionizations. The obtained resolution of $1.7 \mathrm{eV} \mathrm{FWHM}$ at $\mathrm{Si} K \alpha_{1,2}$ lines induced with $20 \mathrm{MeV}$ carbon ions on $\mathrm{Si}, \mathrm{SiO}_{2}$ and $\mathrm{SiC}$ enabled the fine structure to be resolved into multiple ionization $\mathrm{Si} \mathrm{K} \alpha$ $\mathrm{X}$-ray satellite components, which showed clear differences for $\mathrm{K} \alpha \mathrm{L}^{1}, \mathrm{~K} \alpha \mathrm{L}^{2}$ and $\mathrm{K} \alpha \mathrm{L}^{3}$ bands. Apparent average $\mathrm{L}$ vacancy fractions calculated from the measured relative intensities of multiple ionization satellites showed small variations with effective charge on silicon, which is in agreement with the trend observed by other authors. A much stronger variation with effective charge and greater chemical sensitivity was seen in relative $\mathrm{K} \alpha \mathrm{L}^{2}$ intensities.

\section{Acknowledgements}

The authors acknowledge the support from the Croatian Science Foundation (pr. No. 8127) and from the Croatian Centre of Excellence for Advanced Materials and Sensors.

\section{References}

1 R. L. Watson, A. K. Leeper and B. I. Sonobe, Nucl. Instrum. Methods, 1977, 142, 311-316.

2 Y. Mokuno, Y. Horino, T. Tadić, M. Terasawa, T. Sekioka, A. Chayahara, A. Kinomura, N. Tsubouchi and K. Fujii, Nucl. Instrum. Methods Phys. Res., Sect. B, 1998, 136-138, 368-372.

3 D. Fischer and W. Baun, Spectrochim. Acta, 1965, 21, 443-450.

4 W. Baun and D. Fischer, Spectrochim. Acta, 1965, 21, 14711478.

5 M. Tanaka, M. Takeguchi and K. Furuya, Ultramicroscopy, 2008, 108, 1427-1431.

6 N. Nelms, D. F. Anagnostopoulos, O. Ayranov, G. Borchert, J. P. Egger, D. Gotta, M. Hennebach, P. Indelicato, B. Leoni, Y. W. Liu, B. Manil, L. M. Simons and A. Wells, Nucl. Instrum. Methods Phys. Res., Sect. A, 2002, 484, 419-431.

7 G. Ghiringhelli, A. Piazzalunga, C. Dallera, G. Trezzi, L. Braicovich, T. Schmitt, V. N. Strocov, R. Betemps, L. Patthey, X. Wang and M. Grioni, Rev. Sci. Instrum., 2006, 77, 113108.

8 K. Maeda, K. Hasegawa, M. Maeda, K. Ogiwara and H. Hamanaka, X-Ray Spectrom., 2005, 34, 389-392.

9 S. Fazinić, M. Jakšić, L. Mandić and J. Dobrinić, Phys. Rev. A, 2006, 74, 062501.

10 L. Mandić, S. Fazinić and M. Jakšić, Phys. Rev. A, 2009, 80, 042519.

11 S. Fazinić, L. Mandić, M. Kavčič and I. Božičević, Spectrochim. Acta, Part B, 2011, 66, 461-469.

12 S. Fazinić, L. Mandić, M. Kavčič and I. Božičević, J. Anal. At. Spectrom., 2011, 26, 2467.
13 European X-ray Spectrometry Association, http:// www.exsa.hu/.

14 J. L. Campbell, J. A. Maxwell, S. M. Andrushenko, S. M. Taylor, B. N. Jones and W. Brown-Bury, Nucl. Instrum. Methods Phys. Res., Sect. B, 2011, 269, 57-68.

15 R. L. Watson, F. E. Jenson and T. Chiao, Phys. Rev. A, 1974, 10, 1230-1244.

16 R. L. Watson, A. K. Leeper, B. I. Sonobe, T. Chiao and F. E. Jenson, Phys. Rev. A, 1977, 15, 914-925.

17 T. Narusawa, H. Ohyama, H. Nakashima, S. Hayashi, K. Koyanagi, S. Kumashiro and H. Soejima, Surf. Interface Anal., 1988, 11, 234-242.

18 H. Shigeki, T. Junichi, T. Akira, K. Isao, K. Ikuo, N. Shinji, A. Masatoshi and S. Hiroyoshi, Nucl. Instrum. Methods Phys. Res., Sect. B, 1992, 64, 428-433.

19 D. H. Morse, G. S. Bench, S. P. H. T. Freeman and A. E. Pontau, Nucl. Instrum. Methods Phys. Res., Sect. B, 1995, 99, 427-430.

20 Y. Mokuno, Y. Horino, A. Chayahara, A. Kinomura, N. Tsubouchi, K. Fujii, M. Terasawa, T. Sekioka and T. Mitamura, Nucl. Instrum. Methods Phys. Res., Sect. B, 1997, 130, 243-246.

21 Y. Mokuno, Y. Horino, T. Tadic, M. Terasawa, A. Kinomura, A. Chayahara and N. Tsubouchi, Nucl. Instrum. Methods Phys. Res., Sect. B, 1999, 150, 109-113.

22 K. Kawatsura, N. Takeshima, K. Takahiro, Y. Mokuno, Y. Horino, A. Kinomura, A. Chayahara, N. Tsubouchi, T. Sekioka and M. Terasawa, Nucl. Instrum. Methods Phys. Res., Sect. B, 2001, 181, 128-133.

23 K. Kawatsura, N. Takeshima, T. Imaoku, K. Takahiro, Y. Mokuno, Y. Horino, T. Sekioka and M. Terasawa, Nucl. Instrum. Methods Phys. Res., Sect. B, 2002, 193, 877-882.

24 M. Jakšić, I. Bogdanović Radović, M. Bogovac, V. Desnica, S. Fazinić, M. Karlušić, Z. Medunić, H. Muto, Ž. Pastuović, Z. Siketić, N. Skukan and T. Tadić, Nucl. Instrum. Methods Phys. Res., Sect. B, 2007, 260, 114-118.

25 S. Fazinić, I. Božičević Mihalić, T. Tadić, D. Cosic, M. Jakšić and D. Mudronja, Nucl. Instrum. Methods Phys. Res., Sect. B, 2015, 363, 61-65.

26 T. Tadić, M. Jakšić and I. Božičević, X-Ray Spectrom., 2009, 38, 222-228.

27 T. Tadić, I. Božičević and M. Jakšić, X-Ray Spectrom., 2011, 40, 147-152.

28 M. E. Dinardo, A. Piazzalunga, L. Braicovich, V. Bisogni, C. Dallera, K. Giarda, M. Marcon, A. Tagliaferri and G. Ghiringhelli, Nucl. Instrum. Methods Phys. Res., Sect. A, 2007, 570, 176-181.

29 J. Szlachetko, J.-C. Dousse, J. Hoszowska, M. Berset, W. Cao, M. Szlachetko and M. Kavčič, Rev. Sci. Instrum., 2007, 78, 093102.

30 C. G. Dodd and G. L. Glen, J. Appl. Phys., 1968, 39, 5377.

31 T. Okura, H. Inoue, T. Kanazawa, S. Endo, S. Fukushima and Y. Gohshi, Spectrochim. Acta, Part B, 1990, 45, 711-717.

32 N. Kikuchi, T. Maekawa and T. Yokokawa, Bull. Chem. Soc. Jpn., 1979, 52, 1260-1263.

33 J. Hasegawa, T. Tada, Y. Oguri, M. Hayashi, T. Toriyama, T. Kawabata and K. Masai, Rev. Sci. Instrum., 2007, 78, 073105. 
34 Z. Liu, S. Sugata, K. Yuge, M. Nagasono, K. Tanaka and J. Kawai, Phys. Rev. B: Condens. Matter Mater. Phys., 2004, 69, 035106.

35 E. W. White and G. V. Gibbs, Am. Mineral., 1967, 52, 985.

36 S. Sakka and K. Matusita, J. Non-Cryst. Solids, 1976, 22, 5766.

37 S. Sakka and A. Senga, J. Mater. Sci., 1978, 13, 505-512.

38 T. Okura, G. Sudoh, H. Inoue and T. Kanazawa, J. Mater. Sci., 1995, 30, 1033-1036.

39 M. Motoyama and G. Hashizume, Bull. Chem. Soc. Jpn., 1972, 45, 38-42.

40 E. Asada, Jpn. J. Appl. Phys., 1976, 15, 1417-1420.

41 G. Graeffe, J. Juslen and M. Karras, J. Phys. B: At. Mol. Phys., 1977, 10, 3219.

42 S. Santra, A. C. Mandal, D. Mitra, M. Sarkar, D. Bhattacharya and P. Sen, Nucl. Instrum. Methods Phys. Res., Sect. B, 2002, 197, 1-10.

43 E. Perino, M. T. Deluigi, R. Olsina and J. A. Riveros, X-Ray Spectrom., 2002, 31, 115-119.

44 F. Hopkins, A. Little, N. Cue and V. Dutkiewicz, Phys. Rev. Lett., 1976, 37, 1100-1103.

45 R. L. Watson, A. K. Leeper, B. I. Sonobe, T. Chiao and F. E. Jenson, Phys. Rev. A, 1977, 15, 914-925.

46 J. A. Demarest and R. L. Watson, Phys. Rev. A, 1978, 17, 13021313.

47 M. Kavčič, Phys. Rev. A, 2003, 68, 022713.

48 K. Maeda, K. Hasegawa, H. Hamanaka and K. Ogiwara, Nucl. Instrum. Methods Phys. Res., Sect. B, 1998, 134, 418-426.
49 J. A. Bearden, Rev. Mod. Phys., 1967, 39, 78-124.

50 K. Yokoi, H. Oohashi, Y. Ito, T. Tochio and T. Shoji, Radiat. Phys. Chem., 2006, 75, 1461-1464.

51 S. P. Limandri, R. D. Bonetto, A. C. Carreras and J. C. Trincavelli, Phys. Rev. A, 2010, 82, 032505.

52 W. F. Demjochin and W. P. Satschenko, Röntgenspektren und Chemische Bindung, 1966, 58-64.

53 S. P. Limandri, A. C. Carreras, R. D. Bonetto and J. C. Trincavelli, Phys. Rev. A, 2010, 81, 012504.

54 E. I. Esmail, C. J. Nicholls and D. S. Urch, Analyst, 1973, 98, 725.

55 Y. Takahashi, Bull. Chem. Soc. Jpn., 1973, 46, 2039-2044.

56 D. Urch, Mineral. Mag., 1989, 53, 153-164.

57 P. Ordejón, Solid State Commun., 1992, 83, 175-178.

58 J. Scofield, Phys. Rev. A, 1974, 9, 1041-1049.

59 S. Fazinić, T. Tadić, I. Bogdanović, M. Jakšić, I. Orlić and V. Valković, Nucl. Instrum. Methods Phys. Res., Sect. B, 1996, 114, 232-236.

60 V. Horvat, R. L. Watson and Y. Peng, Phys. Rev. A, 2006, 74, 022718.

61 R. L. Watson, T. Chiao and F. E. Jenson, Phys. Rev. Lett., 1975, 35, 254-257.

62 R. L. Watson, V. Horvat and Y. Peng, Phys. Rev. A, 2008, 78, 062702.

63 C. R. Vane, L. D. Hulett Jr, S. Kahane, F. D. Mcdaniel, W. T. Milner, G. D. O'Kelley, S. Raman, T. M. Rosseel, G. G. Slaughter, S. L. Varghese and J. P. Young, Nucl. Instrum. Methods Phys. Res., Sect. B, 1984, 3, 88-93. 